\title{
Concepções e Expectativas de Alunos na Educação de Jovens e Adultos acerca do Ensino de Ciências: Um Estudo Investigativo
}

\section{Student Conceptions and Expectations in Youth and Adult Education about Science Teaching: An Investigative Study}

\author{
Cristiane Cordeiro Vasques (cristianecvasques@gmail.com) \\ Instituto Federal do Rio de Janeiro (IFRJ) - Programa de Pós-graduação em Ensino de Ciências \\ (PROPEC) \\ Jorge Cardoso Messeder (jorge.messeder@ifrj.edu.br) \\ Instituto Federal do Rio de Janeiro (IFRJ) - Programa de Pós-graduação em Ensino de Ciências \\ (PROPEC)
}

Resumo: Este estudo apresenta o relato de uma pesquisa realizada em uma escola municipal do Rio de Janeiro sobre as expectativas e concepções dos alunos da EJA (Educação de Jovens e Adultos) utilizando o ensino de ciências como viés investigativo. Foram realizadas entrevistas para coleta de dados sobre a percepção dos alunos sobre o ensino de ciências e uma roda de conversa onde se buscou socializar as informações coletadas nas entrevistas e possibilitar um espaço dialógico para a troca dos saberes. Neste estudo, utilizamos a fundamentação apresentada por autores como Pozo e Gómez Crespo (2009), Paulo Freire (2005), Nélio Bizzo (2012) e outros para a compreensão dos processos identificados. A pesquisa favoreceu a percepção de um aluno participativo e interessado em realizar conexões produtivas, contradizendo as impressões iniciais relatadas pelos professores em situações cotidianas nas salas de aula.

Palavras-chaves: Educação de Jovens e Adultos; juvenilização; ensino de ciências; relação dialógica.

\begin{abstract}
This study presents the report of a research carried out in a municipal school of Rio de Janeiro about the expectations and conceptions of the students of the EJA (Youth and Adult Education) using science teaching as an investigative bias. Interviews were conducted to collect data on students' perceptions of science teaching and a conversation wheel where we sought to socialize the data collected in the interviews and enable a dialogical space for the exchange of knowledge. In this study, we utilized the reasoning presented by authors as Pozo and Gómez Crespo (2009), Paulo Freire (2005), Nélio Bizzo (2012) and others for understanding the indentified processes. The research favored the perception of a participative and interested student in making productive conections, contradicting the initial impressions reported by teachers in everyday situations in classrooms.
\end{abstract}

Keywords: Youth and Adult Education; youthfulness; science teaching; dialogical relationship.

\section{INTRODUÇÃO}


Nas salas de professores é comum ouvirmos comentários sobre os alunos e seu restrito interesse pelas atividades escolares. Com a Educação de Jovens e Adultos (EJA) não é diferente, em especial sobre as classes correspondentes ao Ensino Fundamental II. A juvenilização do ensino noturno é um argumento marcante ao fundamentar estes relatos. Muitos professores já experientes no trabalho com a EJA, tornam-se saudosistas ao relembrar os tempos em que as classes eram formadas fundamentalmente por adultos. Pereira Leão (2011) afirma que o "rejuvenescimento" da EJA é um fenômeno social que deve ser investigado, procurando-se compreender as rupturas, as alternativas e os novos desafios que provoca" (p. 69).

No entanto, com relação aos alunos adultos, também ouvimos que a eles faltam conhecimentos sobre a rotina escolar, sobre os procedimentos metodológicos comumente adotados em sala de aula, sobre o uso adequado dos materiais didáticos, enfim, sobre o fazer escolar propriamente dito. Esses relatos são usados para justificar uma participação menos efetiva por parte desses alunos.

Pozo e Gómez Crespo (2009) fazem uma análise do famoso "desinteresse” dos alunos.

Quando se pergunta a professores de ciências pelos problemas que mais os inquietam em seu trabalho docente, raramente citam como primeira preocupação que os alunos não consigam diferenciar entre peso e massa, ou que não sejam capazes de cálculos proporcionais; o que geralmente mencionam é a falta de disciplina ou, simplesmente, a falta de educação dos alunos, o pouco valor que concedem ao conhecimento e, sobretudo, a falta de interesse pela ciência e pela aprendizagem $(2009$, p.30).

A questão da falta de interesse por parte dos alunos parece ser um obstáculo à prática docente. Mas o que pensam os alunos sobre o que realizam na sala de aula e na escola? Como percebem este espaço? Que expectativas o trazem de volta ao ambiente escolar? Que concepções têm sobre a importância dos conhecimentos adquiridos na escola em sua vida cotidiana?

Na busca para compreender as concepções e expectativas dos alunos da EJA ao retornarem à escola e como estas concepções podem interferir em sua participação em sala de aula, foi realizada uma pesquisa, tendo como viés uma determinada área do conhecimento - o Ensino de Ciências. O conhecimento científico carrega forte articulação com o dia a dia, nas vivências cotidianas, e está intimamente relacionado com a curiosidade presente no imaginário dos alunos, em especial dos mais jovens, sendo facilitadora na proposta de uma conversação sobre o universo escolar. 
A EJA considera, ou deveria considerar, as experiências trazidas pelos alunos, onde as temáticas envolvendo os conhecimentos científicos estão sempre presentes, ainda que camufladas nos saberes e explicações do senso comum. Para o aluno da EJA, esta conexão entre os saberes escolares e as questões da vida cotidiana pode representar um elo bastante relevante e fortalecedor em sua decisão de retorno ao universo educacional.

Alvares (2010) nos ensina que os alunos jovens e adultos possuem três espécies de saberes: um saber sensível, corporal, anterior às representações simbólicas; um saber do trabalho, construído no contexto do fazer; e um saber cotidiano, social e histórico, resultante das experiências vividas. O conhecimento escolar configura-se como uma espécie de releitura de suas experiências cotidianas, ressignificando os saberes construídos em sala de aula. Isso implica em que o aluno perceba que tais conhecimentos podem ter alguma ressonância em sua vida real, podendo de fato fazer a diferença em suas opções e escolhas.

Bizzo (2012) afirma que "os conteúdos científicos abordados na escola devem ser atualizados - quando não corrigidos, de modo a aproximar o que se ensina na escola daquilo que a sociedade efetivamente demanda" (p. 169). O retorno à escola, muitas vezes, é fruto de grande esforço individual para os alunos da EJA, e é preciso que os conhecimentos e saberes produzidos tenham significado social e contribuam para a emancipação desses sujeitos.

\section{ALGUNS PRESSUPOSTOS TEÓRICOS}

A juvenilização da EJA é um processo que vem ocorrendo nos últimos anos gerando maior heterogeneidade nas salas de aula. Antes, a matrícula dos alunos a partir de 15 anos ocorria pela necessidade de serem inseridos no mercado de trabalho informal ou pela conquista de uma vaga em algum projeto esportivo. Atualmente, a maior incidência deve-se às estratégias de solução do ensino regular para problemas disciplinares, distorção série-idade e/ou insucesso escolar.

Em muitas situações, em especial nas classes de segundo segmento, a chegada desses sujeitos, excluídos do ensino regular, causa impactos negativos nas salas de aula, devido ao distanciamento de interesses e dificuldade na comunicação entre os mais jovens e os alunos adultos, necessitando da intermediação direta do professor e de constantes ajustes metodológicos. 
Na dinâmica das salas de aula, comumente concebidas nos padrões do ensino regular, estes alunos são recebidos como aqueles que estão fora do propósito pensado para a EJA - ensino noturno para alunos trabalhadores que necessitam retomar seu fluxo de escolaridade. A multiplicidade de interesses, expressões e comportamentos constituem para o professor uma demanda diferenciada, fazendo-o optar, muitas vezes, por práticas pedagógicas que lhe favoreça o controle disciplinar como forma de gestão e prevenção de conflitos. Dayrell (2011), em seus estudos sobre a juventude e a Educação de Jovens e Adultos, assegura

O que se constata é que boa parte dos professores de EJA tende a ver o jovem aluno a partir de um conjunto de modelos e estereótipos socialmente construídos e, com esse olhar, correm o risco de analisá-los de forma negativa, o que os impede de conhecer o jovem real que ali frequenta.

No entendimento de Silva Junior (2017) os mais jovens são excluídos de maneira subjetiva, e como uma via conciliatória esta heterogeneidade "demanda efetiva dialogicidade e ampliação nas reflexões das relações interpessoais entre os discentes e desses com os docentes" (p. 96). Assim também, Alvares (2010) assume uma postura de entendimento possível na convivência entre diferentes faixas geracionais nas salas de aula da Educação de Jovens e Adultos ao defender que

A presença de jovens, adultos e idosos numa mesma sala de aula conforma um cenário fértil para as situações de ensino e aprendizagem. A diversidade de gerações, de experiências de vida, de valores, de tradições culturais, de maneiras de falar e de visões de mundo são aspectos que se somam e podem gerar estratégias fecundas se forem trabalhados positivamente e se as diferenças não forem transformadas em desigualdades pelo professor de EJA (ALVARES, 2010, p. 82).

Os três autores citados em nossa reflexão alinham a questão da heterogeneidade nas turmas de EJA atribuindo ao professor um papel preponderante no acolhimento e mediação nas relações que se estabelecem no grupo. Então, como articular as questões metodológicas a fim de despertar o interesse dos alunos jovens e adultos e realizar um trabalho efetivo de integração e ampliação dos saberes que resulte em novas aprendizagens?

Encontramos em Pozo e Gómez Crespo (2009) um estudo que relaciona uma análise dos processos de sucesso e fracasso na aprendizagem e o ensino de ciências, sendo algo que muito nos favorece nesta pesquisa. Segundo os autores, a falta de motivação é um grande obstáculo à realização do trabalho dos professores, sendo apontada como uma das principais causas de insucesso dos alunos. Os autores propõem 
uma reflexão: "os alunos não aprendem porque não estão motivados, mas por sua vez, não estão motivados porque não aprendem" (ibid, 2009, p.40). Nesse sentido, os autores vão deslocando o foco da motivação somente da responsabilidade do aluno e afirmam que ela é também "um resultado da educação que recebem e, em nosso caso, de como lhes é ensinada a ciência" $(2009$, p.40).

Ainda na análise dos estudos de Pozo e Gómez Crespo (2009) localizamos considerações sobre os sistemas de recompensa como elementos motivadores aos alunos, que até funcionam, em certa medida. Estes sistemas consistem em relacionar o ato de estudar com o recebimento de algo externo ao próprio conhecimento - fatores extrínsecos - (receber um presente da família, ser aprovado etc.). Esta estratégia apresenta suas fragilidades quando o aluno evidencia valorizar pouco o sucesso ou o fracasso escolar, demostrando não atribuir sentido ao que está estudando/aprendendo, pois na contrapartida estão as necessidades sociais, que em geral lhes chamam muito mais atenção.

Destacamos, entretanto, que se o esforço empreendido for apenas pelo resultado imediato de uma avaliação, ou mesmo para garantir uma aprovação, provavelmente essa motivação não lhes garantirá a permanência dos conceitos aprendidos. Estes recursos são característicos das concepções condutistas da aprendizagem, que utilizam o binômio estímulo-resposta nos processos de ensino. Em uma classe para jovens e adultos com práticas pedagógicas alinhadas ao viés das recompensas extrínsecas, temos a educação assumindo um viés ideológico de controle social, ignorando a cultura e o saber popular (FROCHTENGARTEN, 2009).

Porém, Pozo e Gómez Crespo afiançam que "a verdadeira motivação pela ciência é descobrir o interesse, o valor de aproximar-se do mundo, indagando sobre sua estrutura e natureza, descobrir o interesse de fazerem-se perguntas e procurar as próprias respostas". (ibid, 2009, p.43). Esses seriam os fatores intrínsecos, que nascem do desejo de aprender, envolvem o esforço do aluno e a atribuição de sentidos ao que foi estudado/aprendido. Nesta abordagem, Frochtengarten (2009) contribui com esta reflexão apontando que um dos objetivos da EJA é possibilitar a aquisição de conhecimentos e práticas discursivas necessárias à participação social, propósitos que fazem com que o aluno adulto retorne à escola.

O desejo de aprender é, portanto, o ponto de convergência da aprendizagem na Educação de Jovens e Adultos com o que a leitura de Freire (2005) nos inspira - buscar 
como ponto inicial o universo do aluno, conectar o espaço escolar com seu mundo cotidiano e convidá-lo a ir além, usando como flauta mágica o conhecimento científico, um mundo de descobertas e releituras do próprio cotidiano. No entanto, o aluno só se permitirá caminhar com o professor se perceber que seu conhecimento, suas histórias e indagações são valorizados. Mas, isso só se realiza com a garantia da participação, em uma relação dialógica, que muitas vezes exigem mudanças na organização da sala de aula e na condução das atividades pedagógicas. Pozo e Gómez Crespo (2009, p.44) acrescentam que "a motivação não é algo que está ou não está no aluno, mas que é resultado da interação social na sala de aula". E acrescentamos que essa interação se concretiza com a promoção o trabalho cooperativo, a participação ativa e o incentivo ao desenvolvimento da autonomia dos alunos.

Em relação à interação professor-alunos, Bizzo (2012) defende que esta influencia a metodologia de ensino adotada e se configura em três dimensões: a dimensão epistemológica (os conhecimentos necessários à sala de aula), a institucional (as relações político-sociais da sala de aula e da escola) e a dimensão humana (que garante a construção do conhecimento e sua socialização). Desta forma, a concepção de ciência que se pretende implementar e a visão de mundo que se deseja construir, devem ser alvo das reflexões do corpo docente quando da definição do projeto político pedagógico da escola. $\mathrm{O}$ autor sustenta ainda a necessidade de participação do aluno no processo de ensino, ressaltando a importância de o discente elaborar seus pensamentos sobre os conhecimentos que tem a respeito do que será ensinado

O ensino de ciências só pode ser efetivo se professor e alunos tiverem consciência das concepções que têm sobre os fenômenos que querem estudar. Assim, uma das etapas iniciais do ensino é a de levantar opiniões e permitir que os estudantes procurem explicar com suas palavras o que conhecem sobre os mais diferentes fenômenos estudados pela ciência (ibid, 2012, p. 159).

Construir redes com o conhecimento escolar e os conhecimentos que possui, traz aos alunos significado e legitimidade do processo de aprendizagem. Esta possibilidade de refletir sobre o conhecimento que possui, e sobre o que está por adquirir, encontra repouso no conceito de metacognição, uma estratégia de ensino muito relevante no universo da EJA. Ribeiro (2003, p. 110) nos esclarece que a metacognição "diz respeito, entre outras coisas, ao conhecimento do próprio conhecimento, à avaliação, à regulação e à organização dos próprios processos cognitivos". 
A consciência de suas possibilidades, percebendo e refletindo sobre seus próprios processos de aprendizagem, gera uma espécie de automotivação para permanecer em seu percurso formativo. $\mathrm{O}$ aluno da EJA ao retornar à escola por identificar suas próprias necessidades, pode desenvolver, mais facilmente, estratégias metacognitivas, conferindo-lhe maior responsabilização pela sua aprendizagem, aumentando a autoestima e ampliando sua percepção do universo circundante.

Nas classes de Educação de Jovens e Adultos, os alunos, quando incentivados a observar e relatar sobre seus processos de desenvolvimento, em geral, apresentam atitudes de comprometimento, evidenciando maior interesse pelas atividades escolares. Estas habilidades são melhor percebidas em ambientes que promovem maior interação a partir de uma metodologia dialógica. À medida que o aluno é estimulado a falar sobre o que sabe, como compreende determinados conceitos, o que sente ou como percebe as relações entre os conhecimentos, promove uma reflexão sobre os processos a que está submetido, aumentando sua capacidade de auto avaliação sobre a própria aprendizagem.

Como resultante dos processos dialógicos, observamos ainda o compartilhamento de saberes entre os alunos e entre alunos e professores, desenvolvendo a habilidade de ouvir e aprender com as experiências dos demais integrantes do grupo escolar.

\section{METODOLOGIA}

Com base nos objetivos estabelecidos, a pesquisa foi classificada como exploratória, buscando maior aproximação e familiaridade com os alunos. Os procedimentos utilizados ao longo do estudo utilizaram-se do viés da pesquisa participante, favorecendo a relação dialógica entre os participantes do estudo (GIL, 2007).

Para a compreensão sobre como os discentes do PEJA $1^{1}$ e PEJA $2^{2}$ percebem os conhecimentos escolares, como estes conhecimentos podem contribuir com a ampliação de seus saberes e como a apropriação destes conhecimentos pode interferir em sua interação em sala de aula, buscou-se uma ancoragem sócio científica como eixo norteador para a realização de entrevistas individuais com os alunos.

\footnotetext{
${ }^{1}$ PEJA I - Programa de Educação de Jovens e Adultos dos anos iniciais do Ensino Fundamental na rede municipal do Rio de Janeiro (RJ).

${ }^{2}$ PEJA II - Programa de Educação de Jovens e Adultos dos anos finais do Ensino Fundamental na rede municipal do Rio de Janeiro (RJ).
} 
No percurso da pesquisa foram ouvidos 62 alunos do PEJA, sendo 22 do PEJA I e 40 do PEJA II de uma escola municipal da zona oeste da cidade do Rio de Janeiro. Para a coleta de dados, os alunos foram entrevistados sobre como percebem o ensino de ciências na escola. Durante a entrevista foi esclarecido individualmente que o objetivo era conhecer o que os alunos pensam sobre as aulas ministradas no PEJA, em especial sobre as aulas de ciências, e como as informações oferecidas pela escola podem ser relevantes ou não para sua vida cotidiana. Os participantes autorizaram que os dados coletados fossem utilizados para fins de pesquisa com a garantia do anonimato. As entrevistas foram gravadas e as respostas tabuladas e analisadas posteriormente.

As perguntas (serão indicadas em itálico para melhor identificação pelo leitor) iniciais tinham como objetivo conhecer qual a concepção de ciências os alunos possuíam. Neste bloco de perguntas os alunos foram incentivados a refletir sobre o conhecimento científico como parte de seu cotidiano: $O$ que vem a sua mente quando você pensa em Ciências? A Ciência faz parte de sua vida? De que forma?

No segundo bloco de perguntas buscou-se aprofundar ainda mais esta reflexão. Os alunos refletiram a relação que a escola e seus conteúdos de ensino podem ter com a vida diária, se os conteúdos ministrados na escola interferem ou modificam seus valores ou suas atitudes: Você acha importante ter aulas de Ciências? Para que serve aprender Ciências? Você se lembra de algum conhecimento adquirido nas aulas de Ciências que tenha modificado sua maneira de pensar ou agir?

No terceiro bloco de questões foi perguntado sobre o acesso que se tem aos conhecimentos científicos e sobre os profissionais que trabalham com este conhecimento: Em que outros lugares você pode aprender sobre os conhecimentos de ciências? Qual é o profissional que produz o conhecimento científico? E quem deveria divulgá-lo?

Buscou-se, com última questão, saber se o aluno já havia pensado na área de ciências como possibilidade de atuação profissional: $O$ campo da ciência desperta em você algum interesse profissional?

Como devolutiva aos alunos sobre os dados coletados durante a entrevista foi realizada, posteriormente, uma roda de conversa: A Ciência faz parte da sua vida? A atividade foi efetivada com as turmas do PEJA I e do PEJA II em momentos distintos, com o objetivo de ampliar as reflexões sobre o conhecimento científico e estimular os alunos na busca por este conhecimento. 
Melo e Cruz (2014) defendem a utilização das rodas de conversa em contexto de pesquisa, para refinar as relações que se estabelecem nos processos de ensino e aprendizagem. Este recurso metodológico possibilitou a abordagem dialógica com os sujeitos participantes, favorecendo a interação e estimulando a troca de opiniões.

\begin{abstract}
Entende-se que as informações produzidas nesse contexto são de caráter qualitativo, pois as opiniões expressas nessas Rodas de Conversa são 'falas' sobre determinados temas discutidos pelos participantes sem a preocupação com o estabelecimento de um consenso, podendo as opiniões convergirem ou divergirem, provocando o debate e a polêmica. Cabe ao mediador garantir a participação igualitária de todos, bem como atender aos critérios de estruturação da discussão (MELO E CRUZ, 2014).
\end{abstract}

A roda de conversa configurou-se como uma entrevista coletiva ampliando o debate e as reflexões iniciadas nas entrevistas individuais, sem a preocupação de chegar a um consenso sobre as questões levantadas. Desta forma, os dados coletados foram essencialmente de caráter qualitativo. As interações e discussões foram registradas em gravações de áudio e anotações da pesquisadora.

Os objetivos da roda de conversa foram os seguintes: socializar informações sobre a pesquisa em curso; discutir dados levantados nas entrevistas realizadas com os alunos das turmas de PEJA; possibilitar reflexões sobre os diferentes conhecimentos que circulam no espaço social, a ampliação do saber e o sentido da escola para a nossa formação humana; e despertar o interesse pelas aulas de Ciências através da percepção do amplo universo do conhecimento científico e das inúmeras possibilidades de conhecer, refletir e atuar.

\title{
Roteiro da roda de conversa
}

Foram realizadas duas rodas de conversa, sendo uma com os alunos do PEJA I, e outra com os alunos do PEJA II. Para que os dois grupos tivessem acesso às informações que julgávamos relevantes, construímos um roteiro base para sua realização, que será disposto nesta seção. Para que os dois grupos tivessem acesso às informações que julgávamos relevantes, construímos um roteiro base para sua realização, disposto a seguir:

- Boas vindas, agradecimento pela presença e esclarecimentos sobre a pesquisa em curso (objetivos, realização das entrevistas para coleta de dados e devolutiva dos dados coletados);

- Projeção de slides com as perguntas, ilustrações e a ocorrência das respostas mais frequentes para cada uma delas; 
- Espaço para as discussões sobre os diferentes pontos de vista considerados nas respostas dos alunos.

- Exibição do vídeo: A Explosão do Saber $^{3}$ - o vídeo apresenta a evolução do conhecimento científico, a institucionalização da ciência e o aumento exponencial da produção científica com o passar do tempo, destacando o avanço tecnológico e as grandes descobertas da ciência, como as invenções, que facilitaram o deslocamento das pessoas e o advento das vacinas e antibióticos. Faz uma análise da longevidade com significativo aumento da idade média do homem e do crescimento da população mundial, ocasionando muitas mudanças de comportamento;

- Espaço para as considerações sobre as informações trazidas pelo vídeo;

- Apresentação de revistas de divulgação científica e disponibilização do material para leitura e empréstimo aos alunos (Galileu, Ciência Hoje, Super Interessante e Recreio);

- Divulgação de instituições públicas de ensino que oferecem cursos de nível médio técnico na área de ciências na cidade do Rio de Janeiro $\left(\right.$ Fiocruz $^{4}$, FAETEC $^{5}$, IFRJ $\left.^{6}\right)$;

- Encerramento com a música "Enquanto houver sol" 7 .

A atividade foi proposta aos alunos, mas os professores das turmas envolvidas acompanharam a realização, e isso foi um grande diferencial. A realização das rodas de conversa possibilitou uma abordagem marcada pela informalidade e seriedade, ao mesmo tempo, enquanto oportunizou aos professores uma percepção ímpar sobre os alunos. Mais do que uma ferramenta para coleta de dados, a roda de conversa promoveu a interação e o diálogo em um clima amistoso.

\section{DESCRIÇÃO E ANÁLISE DOS RESULTADOS}

Os alunos não demonstraram nenhuma resistência para participar da pesquisa, ao contrário, chegavam curiosos e preocupados em responder às questões com clareza e de forma acertada. A maioria dos alunos do PEJA II evidenciava certa ansiedade para saber se suas respostas estavam certas, por mais que a pesquisadora explicasse que o que

\footnotetext{
${ }^{3}$ Disponível em: https://www.youtube.com/watch?v=fJIlgNLx_aI. Acessado em maio de 2020.

${ }^{4}$ Fiocruz - Fundação Oswaldo Cruz.

${ }^{5}$ FAETEC - Fundação de Apoio à Escola Técnica - Secretaria de Estado de Ciências e Tecnologia - RJ.

${ }^{6}$ IFRJ - Instituto Federal de Ciência e Tecnologia do Rio de Janeiro.

${ }^{7}$ Composição de Sérgio Brito (2003), gravada pela banda Titãs pela Gravadora BMG (2004).
} 
interessava como dado para a pesquisa era a opinião de cada aluno, conhecer seus pensamentos e interesses sobre as atividades realizadas na escola, e que não havia respostas certas ou erradas. Este fato sugeriu a reflexão do quanto é incomum para os alunos compartilharem suas opiniões na escola, como se todas as vezes que fossem chamados a participar deveriam apresentar uma resposta pontual sobre algum conhecimento, e que estas respostas teriam sempre que ser categorizadas como certas ou erradas.

Os alunos do PEJA I participaram sem evidenciar tanta preocupação com o padrão das respostas. Desenvolviam conversas amistosas a partir das perguntas feitas, opinando ou revelando não saber sobre uma questão ou outra, sem maiores constrangimentos. Esse fato desperta nossa atenção. As classes de PEJA I têm apenas um professor para o desenvolvimento das disciplinas curriculares, que são desenvolvidas de maneira integrada, o que pode favorecer maior aproximação com o docente, ou mesmo a realização mais frequente de situações envolvendo a participação dos alunos. A atividade possibilitou a reflexão sobre o nível de interação dos alunos com seus professores, as práticas metodológicas realizadas e como o os conteúdos de ciências estão inseridos no cotidiano das salas de aula.

No primeiro bloco de perguntas, o maior número de respostas coincidentes relacionou a palavra ciências à natureza e às questões de saúde (35 respostas), umas poucas respostas relacionaram à tecnologia (4 respostas), algumas relacionaram à disciplina escolar (6 respostas), e outras variações (10 respostas). Apenas 7 alunos não souberam a que associar. As variações de respostas podem ser observadas no Quadro 1.

Quadro 1 - respostas para a primeira pergunta (primeiro bloco).

\section{O que vem a sua mente quando você pensa em ciências?}

Natureza; saúde; corpo humano; tecnologia; animais; projetos; ser humano; vida; mundo; estudar; aprendizado; células; desenvolvimento; inventar coisas robóticas; criação do mundo; astronomia; plantas; a base de tudo; seres vivos; evolução; medicina; salvar vidas; trabalho; abrir a mente; cientistas; enfermagem; química; planetas; doenças; mato/chá/xarope; uma matéria difícil; os estudos e a professora; debate de religiões.

Ao serem perguntados se a Ciência fazia parte da vida, alguns disseram que não muito (4 respostas). Outros responderam afirmativamente, relacionando as situações do cotidiano como uso de medicamentos e cosméticos, alimentação, saúde e tecnologia (25 respostas). Em relação à natureza, e ao convívio com o meio ambiente, foram 18 
respostas. Alguns relacionaram a aquisição do conhecimento em si como algo favorável à formação do indivíduo (10 respostas). Apenas 5 alunos não souberam responder. $\mathrm{O}$ Quadro 2 apresenta as respostas dadas pelos alunos entrevistados.

Quadro 2 - respostas para a segunda pergunta (primeiro bloco).

\section{A Ciência faz parte de sua vida? De que forma?}

Encontrar a cura de doenças; tomar remédio; creme de cabelo; inventar coisas; bichos; saber mais; esportes; alimentação; beber mais água; saber alguma coisa; se sentir inteligente; dia a dia; saber sobre drogas; corpo humano; socorrer pessoas; fazer pão; uso do celular; respiração; cuidar do planeta; economizar água; o ar; muitas coisas; mais na escola; planeta; aprender sobre o ambiente; minha educação.

No segundo bloco a primeira pergunta era se os alunos julgavam importante ter aulas de ciências. Todos responderam afirmativamente. Ao serem perguntados então, para que serve aprender ciências? As respostas foram diversificadas. Para muitos, aprender ciências serve "para saber mais coisas", evidenciando a relação entre a aquisição do conhecimento científico e os processos de formação (22 respostas). Somente 2 respostas foram relacionadas ao conteúdo escolar. Outro padrão de respostas nos chamou a atenção, as que relacionaram o conhecimento ao campo da ação. Já não bastava o saber, mas o fazer (28 respostas). Uma resposta com 6 ocorrências associou o conhecimento à transformação pessoal. Apenas 4 alunos não souberam responder. As respostas dadas podem ser observadas no Quadro 3.

Quadro 3 - respostas para segunda pergunta do (segundo bloco).

\section{Para que serve aprender ciências?}

Aprender mais; se situar no mundo; aprender melhor as coisas da natureza; saber mais da vida e do ambiente; saber combinar alguns elementos; entender sobre as drogas; fazer coisas extraordinárias (vacinas, remédios); salvar as pessoas; conhecer o corpo humano; melhorar a vida; preservação do mundo; ajudar o planeta; saber mais na prova; ser uma pessoa melhor; saber mais sobre os animais; aprender coisas que eu nem imaginava que existia; aprender sobre o mundo lá fora; ter o conhecimento que precisamos; é tão importante quanto português e matemática; ter pessoas especializadas em ciências; aprender sobre a sexualidade; conhecer o mundo em que a gente vive; fazer a gente focar nas coisas; ficar mais bem informado. 
Ao serem questionados sobre algum conhecimento aprendido na escola, e que pudesse ter modificado seu comportamento, alguns alunos destacaram as informações sobre o lixo, e como elas teriam modificado suas atitudes no cotidiano (4 respostas). Outros relacionaram que informações sobre drogas, saúde e alimentação, foram conteúdos importantes para o esclarecimento das pessoas (10 respostas). Alguns relataram que as informações recebidas na escola ajudaram a entender sobre coisas que nunca tinham ouvido falar, "coisas de ciências" (8 respostas). A maioria respondeu negativamente, dizendo não saber responder, ou que ainda não haviam pensado sobre isso (40 respostas). Era notório o esforço que alguns alunos realizavam para responder tal questão, evidenciando que não tinham uma opinião formada sobre isso, como se até aquele momento não haviam relacionado os conhecimentos apresentados na escola com sua realidade vivencial.

Alguns alunos do PEJA I apresentaram uma fala recorrente ao serem questionados sobre os conhecimentos científicos adquiridos na escola: "ainda não cheguei nesse ponto", ou "ainda não tenho aula de ciências". Estas falas deixaram um alerta sobre a abrangência das práticas pedagógicas realizadas neste segmento, se há necessidade de que as vivências propostas aos alunos sejam mais explicitadas quanto aos objetivos e conceitos construídos; se estes conceitos vêm sendo desenvolvidos de forma interdisciplinar, fazendo com que os alunos não relacionem diretamente à uma área disciplinar; ou se de fato estes conhecimentos têm sido relegados. Seguem as respostas dadas (Quadro 4).

Quadro 4 - respostas para segunda pergunta do segundo bloco.

Você se lembra de algum conhecimento adquirido nas aulas de ciências que tenha modificado sua maneira de pensar ou de agir?

Lixo; drogas; alimentação balanceada; glicose; átomo; células; coração; cérebro; cuidar da natureza; biodiversidade; primeiros socorros; água; planeta; misturar tintas; terrário; o mundo tem mais água do que terra; sistema solar; universo; larvas.

No terceiro bloco de perguntas o professor foi amplamente apontado no papel de produtor do conhecimento científico, e a escola como o lugar de excelência onde se tenha acesso a esses conhecimentos. Analisando as respostas, é interessante observar o lugar idealizado, de destaque e importância, concedido aos professores pelos alunos entrevistados. De um universo de 62 entrevistados, 38 imaginam o professor como 
responsável pela elaboração do conhecimento científico, e 32 elegem a escola como o lugar de primazia ao acesso a estes conhecimentos.

Sobre em que outros lugares você pode aprender sobre os conhecimentos de ciências, em dados quantitativos, obtivemos as seguintes respostas: 32 alunos afirmaram que só na escola se pode ter acesso ao conhecimento; 7 disseram que em casa através da internet e programas de TV; 2 alunos relacionaram o livro didático como fonte de informação sobre a ciência e os conhecimentos científicos; 3 imaginam que somente em locais específicos da área de saúde; 4 afirmaram que somente através de uma formação profissional característica; 8 não atribuíram a nada específico e 5 não souberam responder. Uma fala bastante significativa foi levada para a discussão durante a roda de conversa: "O conhecimento está em todo lugar". Observam-se as respostas no Quadro 5.

Quadro 5 - respostas para primeira pergunta do terceiro bloco.

Em que outros lugares você pode aprender sobre os conhecimentos de ciências?

Somente na escola; em casa; na internet; hospitais; cursos; livros; bibliotecas; vídeos; trabalho; outras pessoas; TV; postos de saúde; no decorrer da vida; olhando pro céu; faculdade; laboratório; qualquer lugar.

Sobre o profissional responsável pela produção destes conhecimentos, 38 alunos responderam que é o professor; 11 atribuíram a cientistas e outros profissionais da área a responsabilidade pelas descobertas e avanços da Ciência, 5 atribuíram aos médicos, e 8 não souberam responder. As respostas foram as seguintes: cientista; pesquisador; médico; professor; químico; descobridores; estudiosos; especialistas em ciências; doutor; pessoas que estudam sobre as plantas.

Sobre o profissional responsável por divulgar os conhecimentos e descobertas científicas, foi observado uma variação nas respostas: 35 atribuíram ao professor; 12 aos jornalistas e meios de comunicação; 5 aos profissionais relacionados à área de ciências; 3 às pessoas em geral, sem especificar a profissão; 7 não souberam responder. As respostas foram: professor; jornalista; cientista; estudantes de ciências; os meios de comunicação; pessoas; médicos; nós mesmos; diretor; a própria sociedade.

Quando perguntados se o estudo da Ciência desperta algum interesse profissional futuro, 10 responderam afirmativamente dizendo que gostam muito das aulas de 
ciências, de conhecer sobre os assuntos relacionados e que já pensaram em buscar uma formação acadêmica e profissional na área; 22 alunos disseram que até aquele momento não tinham pensado neste campo como área de trabalho, que gostaram de participar desta entrevista e poder falar sobre isso, mas que não tinham nenhuma informação sobre as instituições que oferecem formação na área, evidenciando interesse em saber um pouco mais. Os demais responderam que não.

Destacamos aqui uma fala: "Isto é para cientistas, tem que estudar muito". Este registro remete a um autojulgamento de incapacidade de percorrer um caminho longo de estudos, e representa também, o entendimento do funcionamento da Ciência. É um tipo comum de fala, não apenas na EJA, em outros segmentos da educação, que traz visões deturpadas da Ciência, muitas das vezes, geradas pelos meios de mídia e comunicação, e por divulgações científicas menos criteriosas. De acordo com Pombo e Lambach (2017, 243),

De maneira geral, podemos dizer que a superação da visão mitificada de que a produção do conhecimento é restrita a poucos, com características de genialidade e habilidades não convencionais, e de que a produção científica é uma atividade autônoma e neutra, carece tanto realizar e manter pesquisas sobre os resultados que as ações em torno dessas questões têm chegado, como também precisa ser uma meta em todos os níveis de ensino.

Esse último questionamento, sobre considerar a atuação profissional na área de ciências como possibilidade futura, compara-se a sementes deixadas no imaginário dos alunos, especialmente aos de PEJA II, onde muitos não demonstram perspectivas positivas sobre a continuidade dos estudos. Despertar o interesse desses jovens e adultos, oferecer informações sobre as instituições com formação de cursos de nível médio pode significar um incentivo ao final do Ensino Fundamental.

Durante a roda de conversa os alunos participaram com satisfação. Alguns participantes reiteraram a fala que havíamos registrado na entrevista, de que as perguntas feitas despertaram a atenção para esta área do conhecimento, que até aquele momento não tinham percebido o quanto esta disciplina pode ser interessante. Outros relataram que tinham curiosidade sobre muitas coisas, mas que ainda não tinham relacionado que a Ciência está todo o tempo em sua vida.

Alguns alunos comentaram que após a entrevista, e depois da oportunidade de debater sobre ciências, puderam ampliar sua maneira de perceber e pensar sobre o conhecimento científico. Ao final da atividade muitos alunos foram até o local onde as revistas de divulgação científica estavam expostas para folheá-las, e vários, tanto do 
PEJA I como do PEJA II, se interessaram em levá-las para ler. Pozo e Gómez Crespo (2009) trazem uma contribuição sobre a importância da atuação da escola na leitura e releitura das diversas fontes de informação presentes nos espaços sociais.

O aluno é bombardeado por diversos canais de comunicação que proporcionam, praticamente sem qualquer filtro, conhecimentos supostamente científicos que, contudo, podem ser pouco congruentes entre si. Nesse sentido, caberia esperar que a escola, em vez de se considerar como a única fonte de informação científica, servisse para integrar ou reinterpretar essas diversas fontes, permitindo, também, um uso mais discriminativo ou reflexivo delas (...). A escola deve ajudar a reconstruir o saber cultural (2009, p.93).

Os professores responsáveis pelas turmas participantes acompanharam a atividade, sendo bastante produtivo, pois puderam compartilhar das opiniões emitidas pelos alunos e interagir com eles fora do espaço formal da sala de aula, funcionando como espaço de reflexão sobre algumas práticas pedagógicas e sobre o papel que ocupam no imaginário de seus alunos.

A partir das questões aqui apresentadas é importante considerar a interação de processos de conhecimento, comunicação e afetividade para uma aprendizagem mais dinâmica e significativa. Ao contrário do que se tinha como informação das conversas informais nas salas dos professores, a pesquisa oportunizou a percepção de um aluno participativo, colaborativo e interessado em fazer conexões produtivas. A entrevista, utilizada como instrumento de coleta de dados, possibilitou aos alunos a reflexão sobre o conhecimento que é transmitido pela escola (necessidade, importância, legitimidade), assim com a roda de conversa possibilitou a troca de saberes e concepções, e a vivência de um espaço dialógico.

Ressalta-se aqui, a importância de pesquisas direcionadas para o segmento da EJA, no que diz respeito ao ensino de ciências. Pereira, Oliveira e Ferreira (2019), ao realizarem um estudo bibliográfico no período de 2000 a 2018, verificaram que as investigações sobre EJA em Educação em Ciências ainda é incipiente. Com isso, trouxemos nossas contribuições para o fortalecimento desse campo de pesquisa, com resultados que indicam que o caminho percorrido esteve em consonância com nossos objetivos norteadores, que foi possibilitar, aos nossos estudantes da EJA, estímulos para um pensamento mais crítico à ciência que, de fato, está no nosso cotidiano.

\section{CONSIDERAÇÕES FINAIS}


A pesquisa não só trouxe dados relevantes sobre as concepções dos alunos acerca do conhecimento científico, como propiciou aos participantes uma reflexão sobre o ensino de ciências, ressignificando e estimulando as conexões entre o conhecimento formal e o cotidiano. A participação dos professores contribuiu para que pudessem perceber seus alunos por outro ponto de vista, e quem sabe rever suas concepções e práticas na Educação de Jovens e Adultos como espaço de direito para promover a educação ao longo da vida e a inclusão de saberes.

Ao analisar a postura dos alunos durante a entrevista e a progressão das respostas dadas, refletimos sobre o percurso da própria atividade. Muitos alunos foram se apropriando das questões a que estavam sendo convidados a pensar, no início como algo distante e generalizado, e depois como algo mais próximo e realizável. Atravessaram o território dos pensamentos vagos e intuitivos, para o campo das ideias. Apropriaram-se de suas possibilidades de ação ao refletir sobre o conhecimento científico, como se criassem a consciência da força de transformação do conhecimento: "aprender mais", "se situar no mundo", "fazer coisas extraordinárias", "melhorar a vida", "salvar as pessoas", "ajudar o planeta", "encontrar a cura de doenças". É o que podemos afirmar como inegável imersão no conhecimento e atribuição de sentido ao ato de aprender.

As reflexões sobre as diversas experiências dos alunos e suas relações com sua comunidade, seu ambiente e com o mundo, contribuem para a formação de cidadãos capazes de agir com autonomia, responsabilidade e solidariedade. No entanto, a escola necessita acessar estas informações para melhor conhecer seus alunos, ajudando-os a ressignificar estas vivências, agregando-as aos saberes escolares e legitimando o conhecimento constituído. E assim, reafirmar a escola como espaço de convivência social e humana ao longo da vida.

\section{REFERÊNCIAS}

ALVARES, S. C. Educação estética para jovens e adultos: a beleza no ensinar e aprender. São Paulo: Cortez, 2010.

BIZZO, N. Pensamento científico - a natureza da ciência no ensino fundamental.

São Paulo: Melhoramentos, 2012.

DAYRELL, J. A juventude e a Educação de Jovens e Adultos: reflexões iniciais novos sujeitos. In: SOARES, L., GIOVANETTI, M. e GOMES, N. (Orgs.). Diálogos

na Educação de Jovens e Adultos. 4 ed. Belo Horizonte: Autêntica Editora, 2011.

FREIRE, P. Pedagogia do Oprimido. Rio de Janeiro: Paz e Terra, 2005. 
FROCHTENGARTEN, F. Caminhando sobre fronteiras: o papel da educação na vida de adultos imigrantes. São Paulo: Summus, 2009.

GIL, A. C. Como elaborar projetos de pesquisa. 4. ed. São Paulo: Atlas, 2007.

MELO, M. CRUZ, G. Roda de conversa: uma proposta metodológica para a construção de um espaço dialógico no Ensino Médio. Imagens da Educação, v.4, n.2, p.31-39, 2014.

POZO, I.; GOMEZ CRESPO, M. A aprendizagem e o ensino de Ciências - do conhecimento cotidiano ao conhecimento científico. 5. ed. Porto Alegre: Artmed, 2009.

PEREIRA, M.; OLIVEIRA, J. C.; FERREIRA, T. Análise de pesquisas em Educação em Ciências e Ensino de Biologia sobre Educação de Jovens e Adultos (EJA) em periódicos brasileiros. Revista Insignare Scientia - RIS, v. 2, n. 2, p. 100-114, 16 set. 2019. Disponível em:

https://periodicos.uffs.edu.br/index.php/RIS/article/view/10817/7203. Acesso em 25 abr. 2020.

PEREIRA LEÃO, G. Políticas de juventude e Educação de Jovens e Adultos: tecendo diálogos a partir dos sujeitos. In: SOARES, L., GIOVANETTI, M.; GOMES, N. (Orgs.) Diálogos na Educação de Jovens e Adultos. Belo Horizonte: Autêntica Editora, 2011. POMBO, F. M. Z.; LAMBACH, M. As visões sobre ciência e cientistas dos estudantes de química da EJA e as relações com os processos de ensino e aprendizagem. Química Nova na Escola, v. 39, n. 3, p. 237-244, agosto 2017. Disponível em:

http://qnesc.sbq.org.br/online/qnesc39_3/04-QS-50-16.pdf. Acesso em 25 abr. 2020.

RIBEIRO, C. Metacognição: Um apoio ao processo de Aprendizagem. In: Psicologia, Reflexão e Crítica, pp. 109-116. Coimbra: UCP, 2003. Disponível em: https://www.scielo.br/pdf/prc/v16n1/16802.pdf. Acesso em 25 abr. 2020.

SILVA JUNIOR, C. A juvenilização nas turmas de Educação de Jovens e Adultos em um CIEP na comunidade da Maré/RJ: conhecendo seus sujeitos e suas perspectivas. In: NICODEMOS, A. (Org.). Saberes e práticas docentes na Educação de Jovens e Adultos. São Paulo: Paco, 2017. 